\title{
Role of Descriptive geometry course in development of students' spatial visualization skills
}

\author{
Lucia Baranová, Ivana Katreničová \\ Technical university of Košice \\ Faculty of Civil Engineering, Slovakia \\ ivana.katrenicova@tuke.sk \\ Submitted June 15, 2017 - Accepted April 27, 2018
}

\begin{abstract}
Spatial ability is of great importance for successful work in various fields such as computer graphics, engineering, architecture and cartography. A number of studies have demonstrated that Descriptive geometry courses have the potential to develop spatial skills. The aim of this study is to investigate the effect of Descriptive geometry course with the current method of teaching on the spatial skills of students at the Faculty of Civil Engineering at the Technical University of Košice. The study was conducted by a pretest and posttest method. The first grade students studying in the winter term of 2016 to 2017 educational year served as a sample for the study. A significant difference between the pretest and posttest scores was revealed by using the Wilcoxon signed rank test. The findings showed that Descriptive geometry course has a positive impact on development of students' spatial skills. Although, the Descriptive geometry course provides numerous benefits, it is often regarded by students as one of the most difficult courses. The use of dynamic geometry software with the ability to represent three-dimensional space allows students to overcome the difficulties associated with the plot of this course. The future plans within Descriptive geometry teaching include integration of the dynamic geometry software GeoGebra into the educational process which should lead to the innovation and facilitation of the Descriptive geometry course.
\end{abstract}

Keywords: Spatial ability, mathematics education, engineering education $M S C$ : AMS classification numbers 


\section{Introduction}

Geometry teaching plays an important role in mathematical education of students as it contributes to development of their spatial skills [24]. In general geometry is considered as one of the essential components of mathematics concerned with the study of relationships between geometric shapes, figures in space and their properties and applications in the physical world. Since we live in a three-dimensional (3D) world and everything which we use, produce and buy has a 3D geometric shape, the geometry instruction should include the study of $3 \mathrm{D}$ geometry. The branch of geometry which allows the representation of 3D objects in two dimensions is Descriptive geometry.

The descriptive geometry education provides a training of the students' intellectual capability of space perception and graphical presentation. Interconnection of Descriptive geometry with other mathematical topics helps students to associate geometric patterns in the world with several branches of mathematics and enables students to apply knowledge they learned through geometrical topics in problem solving, everyday life and other courses.

One of the most important ability in working with Descriptive geometry is the spatial ability which has a substantial position in human thought and for engineering students is very desirable. The spatial ability came into focus of psychologists and educationalists in the first half of the 20th century. There are not the united definition of the spatial ability in the scientific literature. For example: according to Kahle [13] "Spatial visualization is the ability to manipulate an object or pattern in the imagination.", according to Salthouse [21] "Spatial visualization is the mental manipulation of spatial information to determine how a given spatial configuration would appear if portions of that configuration were to be rotated, folded, repositioned, or otherwise transformed." In our concept, the spatial ability is the skill in solving visually assigned problem in mind. It is widely known that spatial visualization skills and mental rotation abilities are critical for technical and engineering professions. According to Thurstone [25], spatial ability is defined within three spatial factors: the ability to recognize the identity of an object when it is seen from different sights, the ability to imagine the movement or internal displacement among the parts of a configuration, the ability to think about those spatial relations in which the body orientation of the observer is an essential part of the problem. It is possible to categorize components of the spatial ability into five sections: spatial perception, spatial visualization, mental rotations, spatial relations and spatial orientation. People with the spatial ability in high level use all components at the same time in interaction. It is important to note that the skills that make up spatial ability are the results of long learning and training processes and the level of spatial ability may change over time. The assessment of spatial abilities is critical to ensure transfer of learning and can be done using several instruments.

There are few accessible standardized tests of the spatial ability. These tests were created as a part of interviewing for the universities or as a part of intelligence 
tests. Each one of them monitor only some of the spatial ability parts not all of them.

In Europe and Japan is widely used the Mental Cutting Test (MCT) [5]. There are studies using the MCT, for example, to find gender differences in spatial visualization [20] or to evaluate spatial ability of students of mathematics education [22]. The MCT consist of 25 problems and it is projected for 20 minutes. The MCT evaluates the ability to solve so called pattern recognition problems.

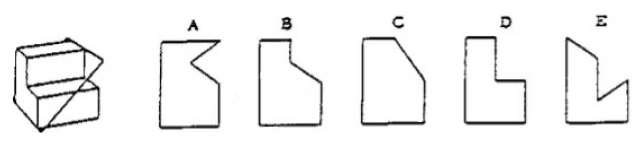

Figure 1: The Mental Cutting Test

In the United States, researchers prefer Purdue Spatial Visualization Test Visualization of Rotation (PSVT: R) [10]. The PSVT: R consist of 30 problems and it is projected for 20 minutes. PSVT: $\mathrm{R}$ evaluates the mental rotation ability.
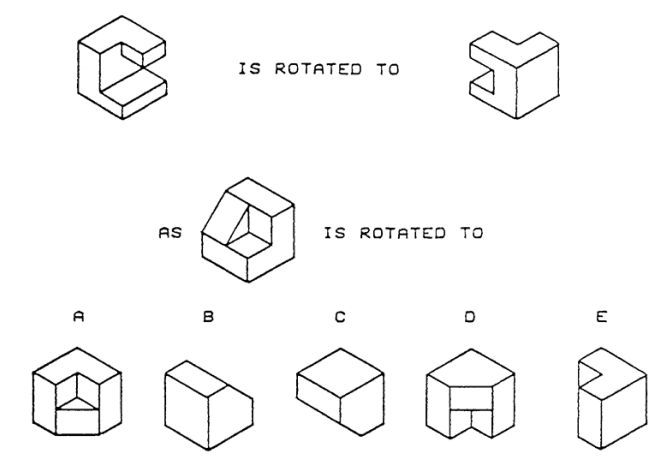

Figure 2: The Purdue Spatial Visualization Test - Visualization of Rotation

The Differential Aptitude Test: Space Relations (DAT: SR) [2] consist of 50 problems and it is projected for 25 minutes. The DAT:SR evaluates the ability of mental rotation and spatial visualization.
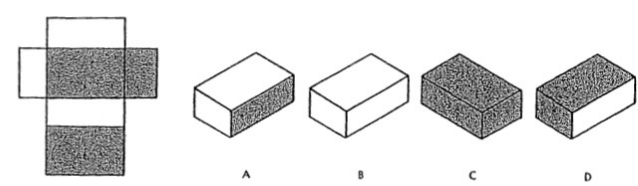

Figure 3: The Differential Aptitude Test: Space Relations

The Mental Rotation Test (MRT) [26] consist of 20 problems and it is projected for 10 minutes. The MRT evaluates the ability of mental rotation ability. 


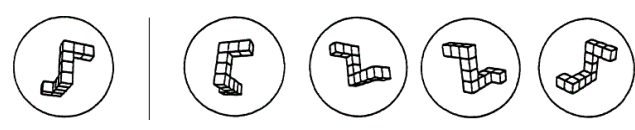

Figure 4: The Mental Rotation Test

The Test of Space Imagination (TPS) [12] consists of three distinct parts and is projected for $13+13+10$ minutes. In the TPS, the component of spatial relations is tested.
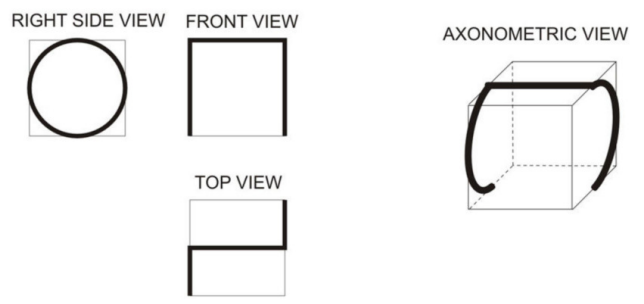

Figure 5: The Test of Space Imagination - Subtest 2 (A Snake in a Cube)

In the recent years, a great deal of attention has been devoted to examination of geometry courses effect on development of spatial ability and the improvement of spatial visualization skills has been found [12, 9, 27, 14, 23]. In addition, numerous studies have shown that spatial ability is positively related to the problem solving ability as well as to a success in mathematics $[7,8,16]$.

The main field of our interest is the examination of the effect of the Descriptive geometry course on the spatial ability of students at the Technical University in Košice at the Faculty of Civil Engineering. Due to the importance of the spatial ability, visual thinking and graphical presentation in the engineering education, Descriptive geometry is still an important part of the basic education of future engineers. At the Faculty of Civil Engineering, full time engineer students have a 2 hour lecture and a 2 hour seminar within the course of Descriptive geometry in the first year of their bachelor's study. During this course, they should pick up the elements of Monge's projection, Axonometry, Central projection, Linear perspective, Planar Intersection of Elementary Solids and the curvilinear surfaces.

Learning geometry is not an easy process because it is highly abstract and difficult to understand, so students do not like geometry related topics. The interest and motivation of the students are very different, and furthermore their pre-knowledge vary very much. 


\section{Results and discussion}

\subsection{Data collecting tool}

The course of Descriptive geometry is carried out at the Faculty of Civil Engineering for the first grade engineering students at the Faculty of Civil engineering and for the first grade students of the Faculty of Art within their bachelor's study. The sample of our study was 160 students of the first grade studying in the winter term of 2016 to 2017 educational year. pretest and posttest were given to the participants at the beginning and at the ending of the 13 weeks winter term. 160 students took pretest which was a paper - pencil test consisting with 4 practical tasks. Time of solution was set to ten minutes. During the winter term the Descriptive geometry lectures and seminars went on. On the seminars students worked with the traditional paper - pencil method. 134 students took posttest consisting of 4 analogical practical tasks after the winter term. For statistical evaluation, only the students who participated on the pretest and posttest as well were taken into consideration so that 119 samples of students were at the disposal.

The main goal was to find out if there is a significant difference between the pretest and the posttest scores of the students. Taken into account the most common test for assessment of spatial ability (MCT and PSVT:R test only specific spatial ability factors.), the test for our possibilities was adjusted and created. The test questions have been constructed with the increasing difficulty and focused on spatial ability testing. The test questions were not in the contents of the Descriptive geometry course. Four questions were chosen on the basis of the spatial ability definition by [25]. Each question is concerned to specific part of spatial ability (3D view, rotation, from $2 \mathrm{D}$ to $3 \mathrm{D}$ view, cutting, multiview projection). Since, students from different types of high schools attend Faculty of Civil engineering, and often without previous experience with descriptive geometry, the first question (Q1) was undemanding and serves to distinguish students with insufficient spatial ability skills (Figure 6).

Q1: In the figure, a body composed of identical blocks is given. The neighbouring blocks are bonded by whole walls. Determine the number of blocks in the body.
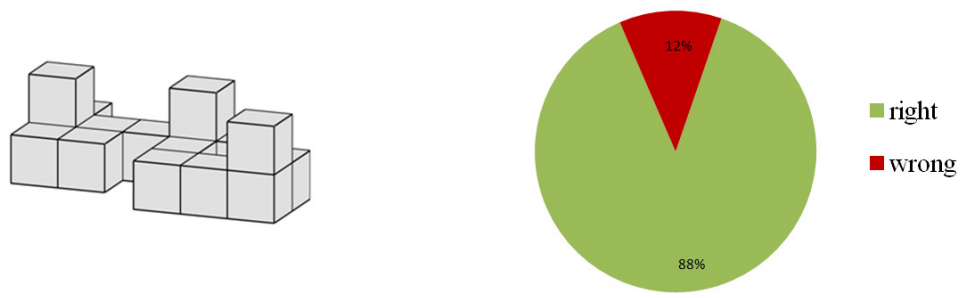

Figure 6: Results analysis of the pretest question Q1

The second question (Q2) was focused on the ability to recognize the identity of an object when it is seen from different sights. Students were required to identify 
which one of the four possibilities is the actual rotated replica of the geometrical target (Figure 7).

Q2: The following body is given.

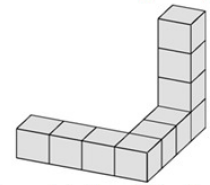

Decide, which of the bodies is the same as the given body.

a)

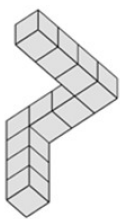

b)

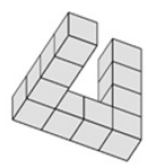

c)

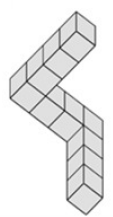

d)

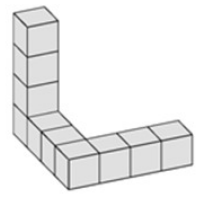

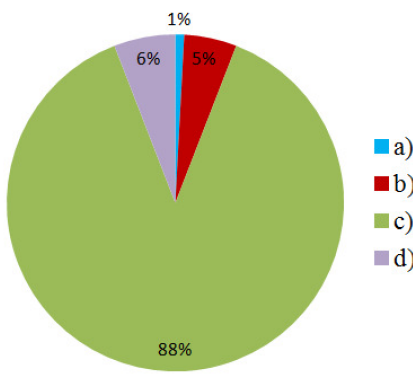

Figure 7: Results analysis of the pretest question Q2

The third question (Q3) referred to the ability to imagine the movement or internal displacement among the parts of a configuration. Students were required to "mentally fold" the two dimensional (2D) pattern and choose the correct 3D objects (Figure 8).

Q3: A net of a cube is given.

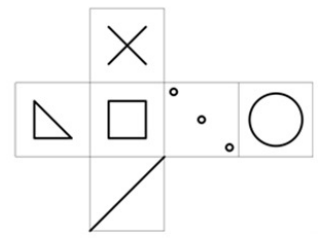

Which of the cubes cannot be compound from the given net?

a)

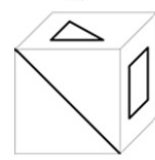

c)

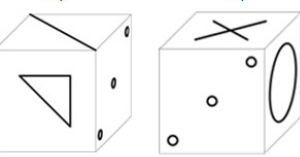

d)

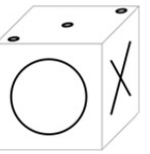

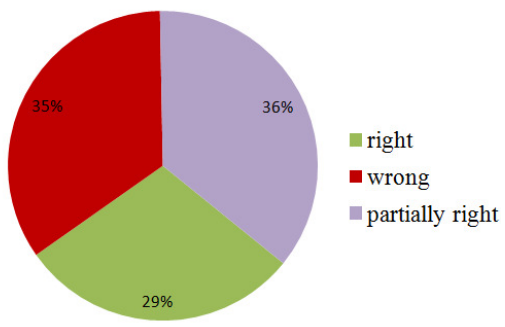

Figure 8: Results analysis of the pretest question Q3

The fourth question (Q4) referred to the ability to think about spatial relations and was measure of student's ability to move from 2D to 3D (Figure 9).

For greater clarity we give one student's solutions of the Q4 pretest and posttest problems.

The Q1 was scored by 1 point for the right and 0 for the wrong answer. The Q2 was scored by 2 points for the right and 0 for the wrong answer. The Q3 was scored by 3 for the right and 0 for the wrong answer. Since the Q3 is multi - choice 
Q4: On the walls of a transparent glass cube, there is a continuous closed line consisting of line segments with endpoints at the verteces of the cube. A vertex can be crossed by the line at most once. There are three views of the cube:

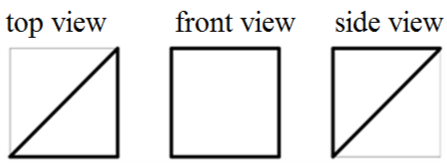

Specify the position of the line on the cube.
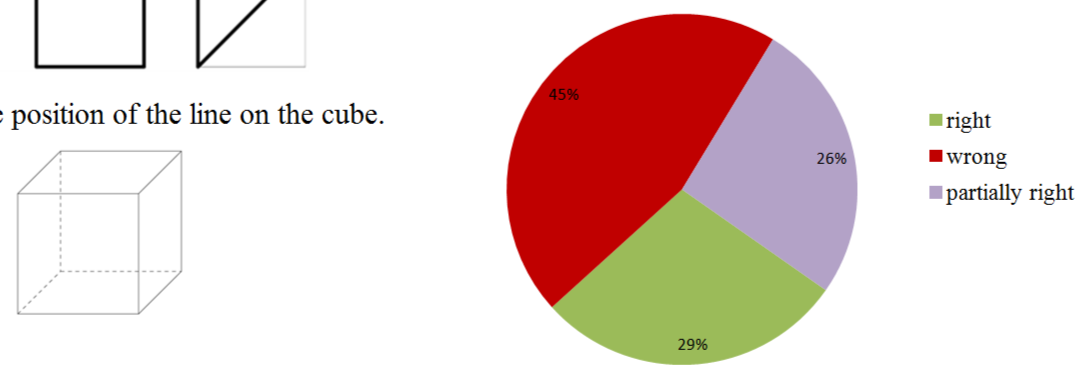

Figure 9: Results analysis of the pretest question Q4

and has two right answers, one right answer was scored by 1 point. The Q4 was scored by 4 for the right and 0 for the wrong answer. For the partial solution of the Q4 a student could get 2 points. Accordingly, a student can get 10 points at most. By means of the Q1, it is possible to distinguish students with essential problems and by means of the last question Q4, we can find students with spatial ability at the high level. The pretest questions with corresponding result analysis are shown in Figures 6, 7, 8, 9 .

\subsection{Data analysis}

Obtained data were examined by two types of analyses. First, descriptive statistics were employed to take a general view of the students' spatial skills before and after the Descriptive geometry course. Second, in order to determine the effects of the treatment on the student's spatial skills, the Wilcoxon signed rank test was used to compare the pretest and the posttest scores. Descriptive statistic of the data obtained from the pretest and the posttest is shown in Table 1.

\begin{tabular}{|l|c|c|c|c|c|c|c|c|}
\hline & \multicolumn{4}{|c|}{ pretest } & \multicolumn{4}{c|}{ posttest } \\
\hline & Min. & Max. & Mean & SD & Min. & Max. & Mean & SD \\
\hline Q1 score & 0 & 1 & 0.88 & 0.30 & 0 & 1 & 0.93 & 0.25 \\
\hline Q2 score & 0 & 2 & 1.76 & 0.65 & 0 & 2 & 1.78 & 0.63 \\
\hline Q3 score & 0 & 3 & 1.24 & 1.20 & 0 & 3 & 1.44 & 1.20 \\
\hline Q4 score & 0 & 4 & 1.66 & 1.60 & 0 & 4 & 1.85 & 1.60 \\
\hline Total score & 1 & 10 & 5.55 & 2.32 & 1 & 10 & 6.01 & 2.32 \\
\hline
\end{tabular}

Table 1: Descriptive statistics of the students' pretest and posttest 


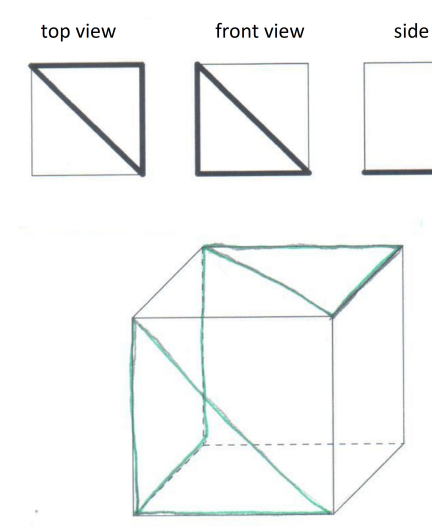

(a) Wrong solution of pretest
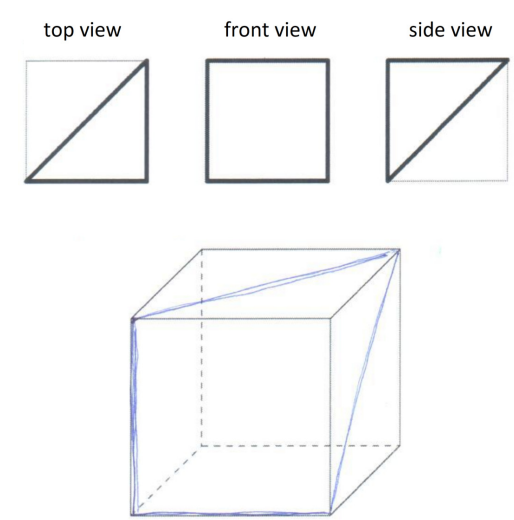

(b) Right solution of posttest

Figure 10: One student's solutions of Q4

Figure 11 displays the results of the students' performance of the pre and the posttest questions. According to Figure 11, the students gave the least correct answer in question 3 and 4 and the most correct answers in Q1 and Q2 in pretest. Similar results were obtained in the posttest, too. As it can be seen in Figure 11, an increase of the students' correct answer averages at each question of the test was uncovered. Although, the increases are close to each other, the highest one is occurred in Q3. These data demonstrate that the course caused an increase in the number of student's correct answers with the considerable improvement in the ability to imagine the movement among the parts of a configuration, ability to move from $2 \mathrm{D}$ to $3 \mathrm{D}$.

Further, since the obtained data did not show normal distribution, the pretest and the posttest scores were analyzed by the Wilcoxon signed rank test at a significance level of 0.05 to determine if this difference which occurred in averages of the students' scores had a statistical significance or not. Table 2 summarizes the results of the Wilcoxon signed rank test analysis performed on the pretest and the posttest.

\begin{tabular}{|l|c|c|c|c|c|}
\hline pretest - posttest & N & Rank Average & Rank Total & z & p \\
\hline Negative rank & 59 & 43.7 & 2579.5 & -1.9255 & 0.0268 \\
\hline Positive rank & 32 & 50.2 & 1606.5 & & \\
\hline Equal & 28 & & & & \\
\hline
\end{tabular}

Table 2: The results of the Wilcoxon signed rank test comparing pretest and posttest scores of students

When Table 2 is examined, it can be seen that after the applied Descriptive geometry course there is difference between the pretest and the posttest scores of the students favoring the posttest $(\mathrm{z}=-1.9255 ; \mathrm{p}<0.027)$. These obtained findings 


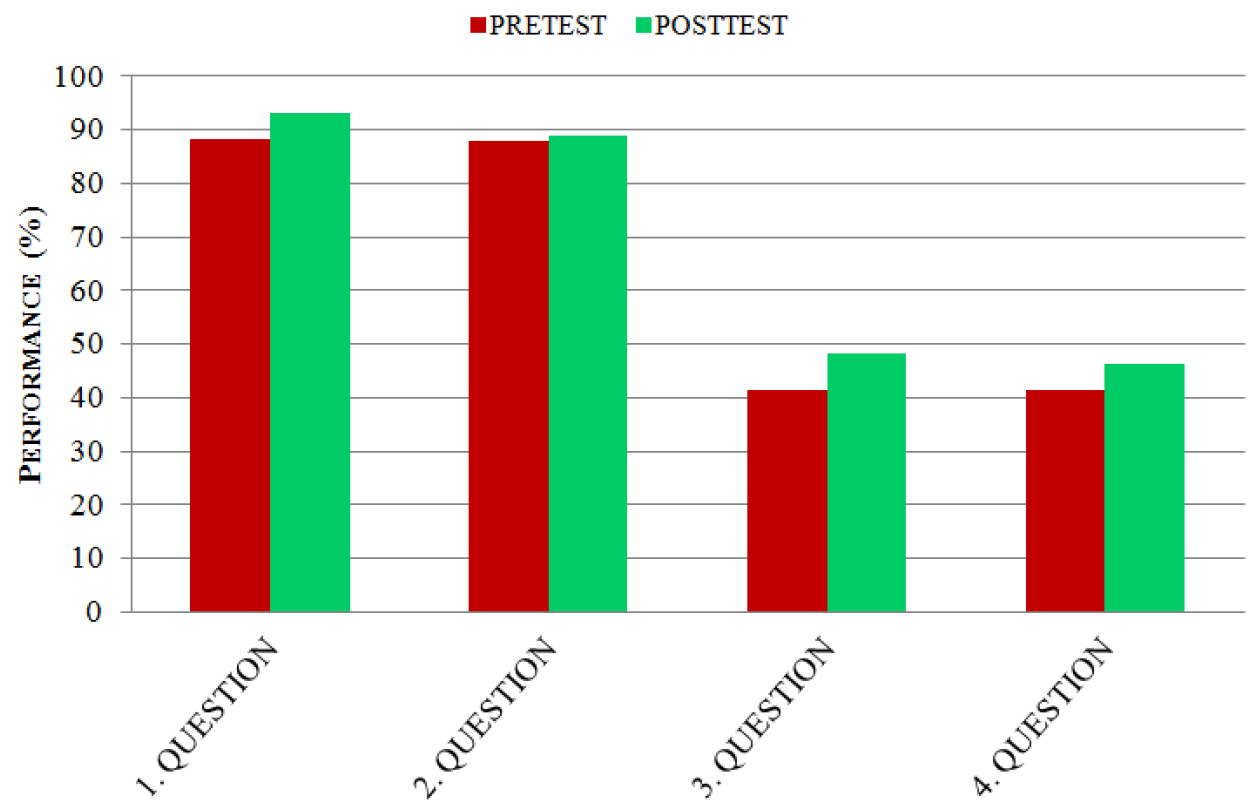

Figure 11: Results of the pre and the posttest

demonstrate that there is a increase in spatial skills of students as a result of the Descriptive geometry course.

\section{Conclusions}

The main purpose of the study was to determine whether the Descriptive geometry course with traditional form of teaching has effects on developing engineering students' spatial skills. According to previous studies spatial skills are a predictor for success in technical education and they are important in engineering training $[17,1]$. The results of testing suggest that many students have problems with imaging a spatial figure and therefore to solve spatial geometry tasks.

The pretest results executed by students at the beginning of the course showed that the students' spatial skills are quite low; the average successfulness of pretest was $55 \%$. The posttest results demonstrate that students' spatial skills can be improved with the help of Descriptive geometry course. The obtained findings are in agreement with related studies $[27,19]$ and confirm significant positive effect of Descriptive geometry on students' spatial skills.

With the computers and software expansion, the trend of study also changes. The current tendency in teaching process lies mostly in the motivation of students to self-study, develop the creativity and practice orientation. Based on that, the form of Descriptive geometry teaching is changing. In the recent years, great inter- 
est has been devoted to implementation of dynamic geometry software into learning environments $[11,6]$. According to these studies, dynamic geometry software is recommended as the tool not only to facilitate the learning geometry process and also for providing visual and effective environments for the creation of geometry constructions as well as interactive exploration through dragging. Furthermore, teaching by using the dynamic geometry software has a great potential to improve spatial visualization skills and has more positive effect on problem solving and spatial skills of students than traditional method [3, 15, 17, 18]. Our aim in the next future is implementation of the dynamic geometry software (GeoGebra [4]) into the learning process at the Faculty of Civil Engineering at the Technical University of Košice in Slovakia. More specifically, our future plans include implementation of interactive animation and virtual solids as promising tools for training spatial skills. In order to better understand the ability of 3D solid models to aid student learning, the future plans include adding additional visual stimulus during displaying of 3D objects, including shadows, lighting, and size. Subsequently, a progress of spatial skills of students taught by innovative method will be verified and compared with the results obtained within the traditional method of teaching.

In this paper we state only the pilot study of the measure of progress of spatial ability. We are thinking to use the Test of Space Imagination in our future work because it consists more tasks of each part of spatial skills.

Acknowledgements. The work was supported by the Ministry of Education, Science, Research and Sport of the Slovak Republic (Project VEGA 1/0078/16).

\section{References}

[1] Ault, H. K., John, S., Assessing and Enhancing Visualization Skills of Engineering Students in Africa: A Comprehensive Study, Engineering Design Graphics Journal, Vol. 74(3) (2010), 12-20.

[2] Bennett, G. K., Seashore, H. G., Wesman, A. G Differential aptitude tests, forms S and T. New York: The Psychological Corporation,(1973).

[3] Budai, L., Improving Problem-Solving Skills with the Help of Plane-Space Analogies, Center for Educational Policy Studies Journal, Vol. 3(4) (2013), 79-98.

[4] Budai, L., GeoGebra in fifth grade elementary mathematics at rural schools, Annales Mathematicae et Informaticae 38 (2011), 129-136

[5] College Entrance Examination Board, CEEB special aptitude test in spatial relations, New York, (1939).

[6] Farrajallah A.-A., The impact of the Employment of Geogebra Software in Acquiring Some Visual Thinking Skills and On the academic Achievement among 8th Grade Students, Journal of mathematics , Vol. 12(2) (2016), 53-64.

[7] Fennema, E., Sherman J., Sex - related differences in mathematical achievement, spatial visualization and affection factors, Educational Research Journal, Vol. 4 (1977), 51-71.

https://doi.org/10.3102/00028312014001051 
[8] Fennema, E., Tartre, L., The Use of Spatial Visualization in Mathematics by Boys and Girls., Journal for Research in Mathematics Education, Vol. 16(3) (1985), 184-206.

https://doi.org/10.2307/748393

[9] Gorska, R., Spatial imagination - an overview of the longitudinal research at Cracow University of Technology, Journal for Geometry and Graphics, Vol. 9 (2005), 201-208.

[10] Guay, R. B., Purdue spatial visualization test: Rotations, West Lafayette: Purdue Research Foundation, (1977).

[11] Javanamani, Z., Alipour V., Role of dynamic geometry software in education and development of solving skills of geometric problems based on Van Hiele model, Sci. Int (Lahore), Vol. 27(3) (2015), 2489-2493.

[12] Juscakova, Z., Gorska, R., A pilot study of a new testing method for spatial abilities evaluation, Journal for Geometry and Graphics, Vol. 7 (2003), 237-246.

[13] Kahle, J. B. The disadvantaged majority: Science education for women, AETS Outstanding Paper, (1983).

[14] Laborde, C., Integration of technology in the design of geometry tasks with Cabrigeometry, International Journal of Computers for Mathematical Learning, Vol. 6 (2001), 283-317.

https://doi.org/10.1023/a:1013309728825

[15] Martín-Gutiérrez, J., Gil, F. A., Contero, M., Saorín, J. L., Dynamic threedimensional illustrator for teaching descriptive geometry and training visualization skills, Computer Applications in Engineering Education, Vol. 21(1) (2013), 8-25. https://doi.org/10.1002/cae.20447

[16] Moses, B. E., The nature of spatial ability and its relationship to mathematical problem-solving, Dissertation Abstracts International, 38(8) (1977), 4640.

[17] Nagy-Kondor, R., The results of a delayed test in Descriptive Geometry, International Journal for Technology in Mathematics Education, Vol. 15(3) (2008), 119-128.

[18] Nagy-Kondor, R., Using dynamic geometry software at technical college, Mathematics and Computer Education, Fall Vol. 42(3) (2008), 249-257.

[19] Németh, B., Sörös, Cs., Hoffmann, M., Typical mistakes in Mental Cutting Test and their consequences in gender differences, Teaching Mathematics and Computer Science, Vol. 5(2) (2007), 385-392.

https://doi.org/10.5485/tmcs. 2007.0169

[20] Németh, B., Hoffmann M., Gender differences in spatial visualization among engineering students, Annales Mathematicae et Informaticae 33 (2006), 169-174.

[21] Salthouse, T. A., Babcock, R. L., Skovroned, E., Mitchell, D. R. D., Palmon, R. Age and experience effects in spatial visualization, Developmental Psychology, Vol. 26(1) (1990), 128-136.

https://doi.org/10.1037/0012-1649.26.1.128

[22] Milin-Šıpuš, Z., ČıžmešıJA, A., Spatial ability of students of mathematics education in Croatia evaluated by the Mental Cutting Test, Annales Mathematicae et Informaticae 40 (2012), 203-216 
[23] Gorska, R. And Sorby, S. Testing Instruments For The Assessment Of 3-D Spatial Skills. Proceedings of the American Society for Engineering Education Annual Conference, (2008).

[24] Stachel, H., What is Descriptive Geometry for?, https://pdfs.semanticscholar.org/daf7/3ef3b50714ba4aa7b74acfb64043c9dbe803.pdf, (2004).

[25] Thurstone, L. L., Primary mental abilities, Psychometric Monographs, 1, (1938).

[26] Vandenberg, S. G., Kuse, A. R. Mental rotations, a group test of three dimensional spatial visualization. Perceptual and Motor Skills, 47, 599-604, (1978). https://doi.org/10.2466/pms.1978.47.2.599

[27] Williams, A., Sutton, K., Allen, R., Spatial Ability: Issues Associated with Engineering and Gender, Proceedings of the 2008 AaeE Conference, Australia (2008), $1-6$. 